\title{
Erratum to: Forecasting environmental migration to the United Kingdom: an exploration using Bayesian models
}

\author{
Guy Abel • Jakub Bijak • Allan Findlay • \\ David McCollum • Arkadiusz Wiśniowski
}

Published online: 15 October 2013

(C) Springer Science+Business Media New York 2013

\section{Erratum to: Popul Environ \\ DOI 10.1007/s11111-013-0186-8}

In the original publication, the acknowledgements section was not included. The text is given below.

Acknowledgments The work was funded by the Foresight programme of the UK Government Office for Science, as a part of the project on "Migration and Global Environmental Change: Future Challenges and Opportunities". The authors are very grateful to all the experts for participating in the survey, as well as to the Editor and three anonymous reviewers of Population and Environment for helping us improve the paper. The remaining errors are exclusively ours. The findings, interpretations, and conclusions expressed in this paper are entirely those of the authors and should not be attributed in any manner to the Government Office for Science, or any of the institutions, with which the authors are affiliated.

The online version of the original article can be found under doi:10.1007/s11111-013-0186-8.

G. Abel

Vienna Institute of Demography, Austrian Academy of Sciences, Vienna, Austria

J. Bijak · A. Wiśniowski

Centre for Population Change, Social Sciences and Demography, University of Southampton,

Southampton, UK

A. Findlay $(\bowtie) \cdot$ D. McCollum

Centre for Population Change, Geography, School of Geography and Geosciences,

University of St Andrews, St Andrews, UK

e-mail: Allan.M.Findlay@st-andrews.ac.uk 